\title{
A Study on the Qiangdi Music Culture and Its Inheritance Problem from the Perspective of Intangible Cultural Heritage
}

\author{
Jin Wang \\ College of Music, China West Normal University, Nanchong Sichuan, 637009, China
}

Keywords: The perspective of intangible cultural heritage, Qiangdi music culture, Inheritance problem.

\begin{abstract}
The Qiangdi music culture is an excellent culture in the minority culture and art of our country. It is included in the list of intangible cultural heritage in our country and is a cultural gem with unique characteristics and history. The main content of this essay is centered on the inheritance and development of the Qiangdi music and culture, and the analysis and exploration of the Qiangdi inheritance and protection from the perspective of intangible cultural heritage. Based on this, the author first describes the basic meaning of the music culture of Qiangdi, and then analyzes the problems and challenges that the music culture inheritance and development of Qiangdi facing in the current environment. Finally, the author puts forward the corresponding strategies and solutions to the problem of how to further inherit and develop the music of Qiangdi music culture from the perspective of intangible cultural heritage.
\end{abstract}

\section{Introduction}

Qiangdi is the historical sediment of more than two thousand years of the Qiang nationality. It integrates the Qiang people's hope for life and their understanding of life for thousands of years. Qiangdi, the crystallization of Qiang people's wisdom, also contains the thoughts and emotions of the Qiang people from generation to generation. As one of the most historical instruments of the Qiang ethnic group and even the Chinese nation, Qiangdi is undoubtedly a veritable artistic treasure. However, with the change of times and the rapid development of society and economy, people's living environment and life style have undergone major changes. Our society gradually becomes the socialist market economy, and the living environment in which we live is increasingly becoming more commercialized. Now that Qiangdi is a minority instrument of the minority ethnic with difficult playing skills and complicated making process, Qiangdi music is facing the pressure of disappearance. Under the new situation, whether Qiangdi, the art of music left from the ancient era, can adapt to the current market environment, can be inherited better and properly protected are the problems and tasks that must be solved urgently.

\section{The origin of the Qiangdi music culture}

Qiangdi is an ancient musical instrument with a long-time history of more than 2000 years. It is closely related to its geographical location and living environment to explore the origin and development of Qiangdi music culture. According to relevant historical records, the Qiang nationality is one of the four ancient ethnics in our country, and is mainly located in remote mountainous areas such as Gansu, Qinghai and western Sichuan in our country. Due to the harsh natural environment and the inconvenient transportation in these areas, as well as the Qiang people live on nomads and hunting, as a result, the Qiang people use their music and songs to make them happy so as to get rid of their depression and loneliness, and over time, the Qiangdi music has been formed. Speaking of making Qiangdi, people use local special arrow bamboo, green bamboo or bitter bamboo to make Qiangdi, the most prominent feature of these bamboos is the low temperature resistant so that they can survive in minus 20 environment. Now it is hard to find the same material with high difficulty. The Qiangdi is thus accompanied by the Qiang people's lives for thousands of years. It is not only as 
their only daily entertainment device, but also as a symbol of the development of the Qiang people's civilization as well as a combination of culture and music.

\section{Problems faced by Qiang Di music culture in inheritance and development}

\subsection{Difficult playing skills of Qiangdi}

As one of the ancient musical instruments of the Chinese nation, Qiang Di is very different in playing method and technique from the current popular musical instruments. As for the playing method, Qiangdi uses the method of changing breath by cheek-bulging with higher difficulty, especially for beginners, and only through years of training and practice can they successfully play a complete tune. Because the method of changing breath by cheek-bulging is essentially a circulatory ventilation skill, performers can change breath in the case of ensuring the air flow is uninterrupted, otherwise it is failed to play. In addition, it requires performers to undergo long-term training and practice ventilation, infuriating, etc., without strong patience and confidence, he cannot persist. Of course, there are many Qiangdi music lovers come and want to learn skills since the ancient time, but because of high difficulties and long training cycle, many people have chosen to give it up halfway. Therefore, it brought inconvenience to the inheritance and development of Qiangdi.

\subsection{Qiangdi's making process is cumbersome with scarce materials}

Not only Qiangdi's playing skill is difficult, but also its making materials are very scarce and difficult to obtain. It is said that the traditional body of Qiangdi is made of arrow bamboo at an altitude of 4,000 meters above the mountain. It may be difficult for ordinary people to climb the mountain with the altitude of 4,000 meters above sea level, therefore, accessing to high-quality arrow bamboo is very difficult, and it requires a very professional mountaineering team to obtain it. Although the requirements for the production of Qiangdi have been reduced, its production process cannot be streamlined. Any unauthorized alteration and reduction of the production process will have a serious impact on the pronunciation and production of Qiangdi. According to the relevant materials, we can see that Qiangdi needs more than 20 procedures from cutting bamboo to the finishing. If one wants to produce high-quality Qiangdi, he may need to have over 30 procedures. In this process, Qiangdi made in ordinary materials should also avoid the problem of rupture. In short, the scarcity of materials and the complicated craftsmanship of Qiangdi is an important factor in the inheritance and development of Qiangdi music culture.

\subsection{Qiangdi's heirs}

Qiang ethnic minority enjoys a long-time history in our country and a special ethnic group with language but no written words at all, therefore, there is no paper-based documentation can be searched for the inheritance of its playing skills and production techniques. The only information can be obtained is the Qiangdi's heirs. They can be said the living body for the inheritance and development of the Qiangdi generations, they also have the clearest and best understanding of the development source and development history. However, at present, only two old artists over 80 years old have been known as the ancient Qiangdi heirs, and most other heirs have died one after another. In addition, the production process and playing skills of Qiangdi cannot be described or documented in written form, so once these heirs die, Qiangdi will not be inherited, it may soon be forgotten by the society, and then disappear. Therefore, the problem of the aging Qiangdi heirs has obviously become a huge stumbling block to the smooth inheritance and development of the Qiangdi music culture.

\subsection{Huge loss of Qiangdi music references and materials}

As mentioned above, many of the materials on Qiangdi cannot be recorded because the Qiang ethnic group only has languages without written words. Even some relevant information and literature have been devastated in the changes of times and the living environment. For example, some unpredictable natural disasters, such as earthquakes, tsunamis, floods and strong winds, these natural destruction phenomenon have caused many places of cultural relics, such as museums, 
cultural centers and cultural research centers, to be destroyed in one second so that some records of audio and video materials as well as scripts of Qiangdi culture art disappeared and caused serious property losses.

\subsection{The impact of market economy and commercialization}

With the implementation and operation of the socialist market economic system, the production and living models in our country have become more and more commercialized, and most of the social activities have obvious economic interests.

In particular, tourism has enjoyed the most rapid development momentum in recent years. However, the traditional fine folk art is unable to adapt to the current living environment, this may be subject to "destruction" without the original ecology and original meanings, and thus it distorts and profanes the history of the Qiangdi music culture. For example, people regard Qiangdi as the souvenirs for tourists to be sold and cheaply sold, because of cheap, coupled with the herd mentality of tourists, the demand for Qiangdi as souvenirs will greatly increase, which will make Qiangdi production techniques use machines instead of manual. In addition, in order to attract tourists as much as possible, some places over-cater to the aesthetic level of tourists, combining Qiangdi performance and modern pop instruments abruptly together, which covers the historical connotation of Qiangdi completely, and the whole performance is neither fish nor fowl. It only can be said that modern people destroy the cultural value of Qiangdi in order to meet their desire and pursuit of the interests of money.

\section{The inheritance and protection of Qiangdi music culture from the perspective of intangible cultural heritage}

\subsection{Enhance people's awareness of cultural conservation, all people jointly inherit it}

The inheritance and protection of Qiangdi music culture from the perspective of intangible cultural heritage requires a long way to go as well as the concerted efforts and struggle of all the people. The key lies in the government and relevant departments of intangible cultural heritage protection, they should correctly guide the Qiang people and tourists from all over China to know and understand the long history and cultural value of Qiangdi, and truly cultivate their awareness of inheritance and protection of Qiangdi. We must enhance the people's awareness of the protection of intangible cultural heritage. We should promote our protection awareness of intangible cultural heritage, knowing Qiangdi is not only an intangible cultural heritage of the Qiang people but also a common cultural heritage of all Chinese people, and all Qiang people should take the initiative to participate in the inheritance and protection work of Qiangdi music culture. The core of inheriting and protecting such arts and culture is human being. Of course, objective protection policies should also continue to be implemented, but only how can all citizens consciously establish the belief that "one has responsibility to protect his own cultural heritage" in their hearts, this consciousness is the most crucial. Specifically, the Qiang people, in particular, should use a variety of channels to promote and publicize Qiangdi music culture so that more people in the society can know and understand it, enjoy it, voluntarily study it and collect it; let more people love to protect it, treat it as a sign of the Qiang ethnic group, and inherit it from generation to generation.

\subsection{Protect and support Qiangdi's heirs}

The direct heritage of Qiangdi music culture is the living human, that is, the so-called successor. However, the current situation is that since the founding of China, most of the older craftsmen skilled in the use of Qiangdi with playing techniques and craftsmanship have all passed away. People who are still alive nowadays are basically old people with limited mobility. Coupled with the lack of a complete and effective inheritance mechanism of the Qiangdi music culture and Qiangdi faces the danger of lost transmission. Therefore, it is very necessary to support and help heirs' life and even spiritual needs. As for the protection and support of intangible cultural heritage heirs, the nation and the government also have promulgated and implemented certain protection policies and measures, 
but none of them has been implemented in real earnest. There is no complete and effective heir protection mechanism. In order to truly inherit and protect the ancient musical instrument of Qiangdi, the relevant government and departments should show their supportive measures to representative heirs of Qiangdi in actions, ensuring that every financial aid can be implemented, and ensuring that heirs of Qiangdi have no worries of life so as to concentrate on the development of Qiangdi music culture. In addition, the government should also ensure that the Qiangdi music successors have a sufficiently high social standing in the region so as to increase the awareness and loyalty of Qiangdi internally to promote the sustainable development of Qiangdi.

\subsection{Making use of internet media to publish and promote Qiangdi}

With the continuous development of society, great progress has been made in various fields such as economy, science and technology as well as culture in our country. In particular, the advent of the Internet era has brought great convenience to people's lives. For Qiangdi music culture heritage and protection, if we can make full use of the current social resources, we can achieve more effective results. For example, the government and relevant departments should actively lead and guide the media enterprises or television stations to make feature films or documentary films that reflect Qiangdi music culture, and then play them at local, provincial and even CCTV stations respectively, introduce and disseminate the historical origin and its development process of Qiangdi music to let more people know and understand Qiangdi, and form a good social effect. In addition, relevant media should also make more reports about the intangible cultural heritage such as Qiangdi, make use of the characteristics of the rapid propagation of new media and networks, and intensify the promotion and publicity of Qiangdi music culture, arousing the concern and attention of the society and promoting Qiangdi to the whole country; people can also use the National Cultural Heritage Day and the Qiang cultural and art exhibitions as well as other forms of success to establish Qiangdi culture and arts brand, and further promote the inheritance and protection process of Qiangdi music culture.

\subsection{Making use of splendid development of tourism to drive the development of Qiangdi music culture}

In recent years, with the social and economic development, people's living standards have been significantly improved. More people are not satisfied with the abundant material life and are starting to chase more spiritual aspects of life. Therefore, in recent years, China's tourism industry has most rapid development momentum. Just taking advantage of opportunities that more and more tourists travel to the Qiang place and other places for tourism, people can regard the Qiang as a tourist attraction to develop it largely so as to attract tourists come to visit and enjoy. People can make use of the tourism party or singing and dancing performances and other forms for people with the Qiangdi as the core finale show. As a result, Qiangdi music culture is attached to the development of the local tourism industry, which not only enhances tourists' attraction to the Qiang area, but also increases people's awareness of the Qiangdi music culture in specific practical activities, which slowly lets residents realize that Qiangdi, as a valuable feature of local ethnic art, is conducive to the better inheritance and development of Qiangdi music culture.

\section{Conclusion}

Qiangdi, as a cultural precipitate and artistic crystallization of more than 3,000 years of the Qiang nationality, is the brainchild of the Qiang people in the ever-changing and developing process of the times. It is also a shining pearl in the history of the development of Chinese civilization. Due to the changing living environment of Qiangdi and the difficulty of making techniques as well as playing skills, which makes Qiangdi, an ancient musical instrument, be at risk of disappearing. Therefore, it is urgent to inherit and protect the music culture of Qiangdi. In order to successfully carry forward the outstanding traditional folk art represented by Qiang Di, it is not only necessary for the government and relevant departments to formulate specific measures, but also every individual in the Qiang ethnic group and every Chinese people to consciously establish their awareness and belief in safeguarding the intangible cultural heritage so that the inheritance and development problem of Qiangdi music 
culture from the perspective of intangible cultural heritage can be successfully solved.

\section{Acknowledgement}

A Study on the Inheritance and Protection of Qiangdi Music Culture from the Perspective of Intangible cultural heritage. The number of the subject: 17YC551, this is the Elite Fund Project.

\section{References}

[1] Ma Lili. A Brief Analysis of the Inheritance and Development of the Major Tune Songs in Henan Province from the Perspective of Intangible cultural heritage, The Voice of Yellow River, 2017-01-06.

[2] Li Tianyi, Tong Yu. A Stufy on Qiangdi Music Culture, Sichuan Drama, 2013-06-25.

[3] Lu Yu, Li Shan. Viewing the Inheritance and Development of Minority Music from the Perspective of Original Folk Songs - Taking Contemporary Problems of Qiang Music Culture as an Example, Music Study, 2008-05-15.

[4] Huan Yali. Northern Shaanxi Story Protection and Inheritance from the Perspective of Intangible cultural heritage, Journal of Yan'an University (Social Science Edition), 2016-10-15.

[5] Zhang Ying. Inheritance and Development of Minority Music from the Perspective of Intangible cultural heritage, Grand View of Music, 2011-9. 